\title{
Retained placenta and postpartum hemorrhage: time is not everything
}

\author{
Denise Franke ${ }^{1} \cdot$ Julia Zepf $^{2} \cdot$ Tilo Burkhardt $^{1} \cdot$ Philipp Stein $^{2,3} \cdot$ Roland Zimmermann $^{1} \cdot$ Christian Haslinger $^{1}(\mathbb{C}$
}

Received: 23 November 2020 / Accepted: 11 March 2021 / Published online: 20 March 2021

(c) The Author(s) 2021

\begin{abstract}
Purpose Postpartum hemorrhage is the major cause of maternal mortality worldwide. Retained placenta accounts for nearly $20 \%$ of severe cases. We investigated the influence of the time factor and retained placenta etiology on postpartum hemorrhage dynamics.

Methods Our retrospective study analyzed a single-center cohort of 296 women with retained placenta. Blood loss was measured using a validated and accurate technique based on calibrated blood collection bags, backed by the post- vs prepartum decrease in hemoglobin. We evaluated the relationship between these two blood loss parameters and the duration of the third stage of labor using Spearman rank correlation, followed by subgroup analysis stratified by third stage duration and retained placenta etiology.

Results Correlation analysis revealed no association between third stage duration and measured blood loss or decrease in hemoglobin. A shorter third stage $(<60 \mathrm{~min})$ was associated with significantly increased uterine atony $(p=0.001)$ and need for blood transfusion $(p=0.006)$. Uterine atony was significantly associated with greater decrease in hemoglobin $(p<0.001)$, higher measured blood loss $(p<0.001)$, postpartum hemorrhage $(p=0.048)$, and need for blood transfusion $(p<0.001)$.

Conclusion Postpartum blood loss does not correlate with third stage duration in women with retained placenta. Our results suggest that there is neither a safe time window preceding postpartum hemorrhage, nor justification for an early cut-off for manual removal of the placenta. The prompt detection of uterine atony and immediate prerequisites for manual removal of the placenta are key factors in the management of postpartum hemorrhage.
\end{abstract}

Keywords Retained placenta $\cdot$ Postpartum hemorrhage $\cdot$ Third stage of labor $\cdot$ Uterine atony $\cdot$ Manual removal of the placenta

\section{Introduction}

Postpartum hemorrhage (PPH) is the leading cause of maternal mortality worldwide: in 2003-2009, hemorrhage accounted for $27.1 \%$ of maternal deaths, over two-thirds of which were classified as PPH [1]. Etiologies include uterine atony, cervical or vaginal laceration, coagulopathy, and in $19.8 \%$ of cases retained placenta [2-5].

Christian Haslinger

Christian.Haslinger@usz.ch

1 Department of Obstetrics, University Hospital Zurich, Frauenklinikstrasse 10, 8091 Zurich, Switzerland

2 University of Zurich, Zurich, Switzerland

3 Institute of Anesthesiology, Cantonal Hospital Winterthur, Winterthur, Switzerland
The third stage of labor starts after the delivery of the child and ends with the delivery of the placenta. A placenta is deemed retained if not expelled within $30 \mathrm{~min}$ postpartum $[6,7]$. Prevalence is higher in high- vs low-income countries (2.7\% vs $1.5 \%$ ) [8]. Expulsion is rapid after vaginal delivery [9]. $90 \%$ of placentas deliver spontaneously within $15 \mathrm{~min}$ [10] (9 min in active management [11]); only $2.2 \%$ remain undelivered at $30 \mathrm{~min} \mathrm{[10].}$

Divergence persists over the optimal timing for manual removal of the placenta (MROP): $\geq 60 \mathrm{~min}$ in Northern Europe vs $\leq 30 \mathrm{~min}$ in Central and Southern Europe [12]. Evidence favoring MROP within $30 \mathrm{~min}$, based on increasing PPH risk with the duration of the third stage of labor, emerged from studies combining women with normal and prolonged third stages $[6,9-11,13-16]$. However, the vast preponderance of normal over prolonged third stages may have skewed the correlation analysis of blood loss over time, 
thus weakening the argument for early MROP, an invasive and potentially unnecessary procedure with attendant risks.

We therefore opted, unlike previous studies, to evaluate the relationship between postpartum blood loss and third stage duration in a cohort confined exclusively to women with retained placenta. We aimed to investigate the influence of time and etiology of retained placenta on PPH, characterize the clinical course of women with retained placenta, and investigate the etiology underlying the pattern of blood loss.

\section{Materials and methods}

The retrospective single-center cohort study was conducted at the University Hospital of Zurich following approval by the local institutional review board (ref. KEK-ZH 2016-1437, October 27 2016). Between January 2009 and December 2016 a total of 9058 births have taken place at the University Hospital of Zurich. 296 women with retained placenta after vaginal delivery of $a \geq 30$-week fetus have been identified and included in our study. This cut-off for gestational age as inclusion criteria was chosen due to the high prevalence of retained placenta in deliveries at an earlier gestational age with a consecutive high risk for confounding factors regarding the primary objective of the study [10, 17]. The placenta was deemed retained if not expelled within 30 min postpartum. Non-inclusion criteria were preexisting coagulopathy and hepatic impairment affecting the prothrombin time.

\section{Data collection}

Using our electronic databases (IntelliSpace Perinatal [OB TraceVue, https://www.usa.philips.com], Perinat, and KISIM [both University Hospital Zurich products]), two experienced clinical researchers (DF and JZ) manually extracted the relevant data on pregnancy course, delivery, maternal and neonatal outcome, perinatal diagnoses and interventions, together with the following primary outcome parameters: pre- and postpartum hemoglobin $(\mathrm{g} / \mathrm{l})$, measured blood loss (MBL, ml), PPH, and need for blood transfusion. Data were also collected on risk factors for increased blood loss (uterine atony, uterine leiomyoma, obstetric laceration, duration of the second and third stages of labor, operative vaginal delivery, previous cesarean delivery, suspected morbidly adherent placenta), feto-maternal characteristics (fetal weight $[\mathrm{g}]$, fetal head circumference $[\mathrm{cm}]$, gestational age [days], maternal body mass index $\left[\mathrm{kg} / \mathrm{m}^{2}\right.$, calculated either pre-pregnancy or in the first trimester], maternal age [years], multiple fetus pregnancy, parity, induction of labor, hypertension), and postpartum maternal anesthesia (general/ regional, admission to intensive care). Gestational age was assessed by first-trimester ultrasonography or, rarely, by calculation from the first day of the last menstrual period.

\section{Management of the third stage of labor}

The third stage of labor was actively managed in all cases after vaginal delivery. Oxytocin $5 \mathrm{IU}$ was routinely given in a 5-min intravenous infusion immediately postpartum [18]. Controlled cord traction was performed. Physical examination by palpating the consistency of uterus was carried out regularly during the third stage of labor by the midwife and the attending physician. Also after the delivery of the placenta, a regular physical examination was performed (in the first hour postpartum every $15 \mathrm{~min}$, in the second hour postpartum every $30 \mathrm{~min}$, afterwards every $4 \mathrm{~h}$ ). In case of suspected retained placenta, ultrasonography was performed and Credé's maneuver was performed only if ultrasonography showed the placenta to be trapped after detaching from the uterine wall. If the placenta did not detach after $15 \mathrm{~min}$, oxytocin infusion was repeated. The anesthesiologist was called if the third stage persisted beyond $30 \mathrm{~min}$ or if MBL exceeded $300 \mathrm{ml}$ at any time. The timing of the different interventions was recorded in the clinical information system and added to our database.

\section{Blood loss parameters}

A fresh drape was placed under the mother immediately after vaginal delivery to quantify blood loss. Successive drapes were weighed on the calibrated neonatal scale present in each delivery suite. A graduated blood collection bag was placed under the mother before MROP or whenever MBL exceeded $300 \mathrm{ml}$ and the placenta had still not detached.

Hemoglobin levels were obtained on admission and between 24 and $48 \mathrm{~h}$ postpartum to calculate the decrease in hemoglobin $(\Delta$-hemoglobin, $\mathrm{g} / \mathrm{l})$.

According to the WHO, PPH was defined as blood loss exceeding $500 \mathrm{ml}$ in $24 \mathrm{~h}$. [7, 19]

\section{Manual removal of the placenta}

MROP was performed on the obstetric ward after anesthesia by manual exploration of the uterine cavity. Suspected remaining tissue was treated by ultrasound-guided curettage and all women received ceftriaxone $1 \mathrm{~g}$ intravenously. Blood loss was totaled at the end of the procedure. When atonic PPH was detected immediate MROP was indicated. In nonactively bleeding women with retained placenta, MROP was indicated after $30 \mathrm{~min}$. From the point of indication (30 $\mathrm{min}$ postpartum in the non-bleeding patient) the anesthesiologist was called and everything was prepared for MROP. 


\section{Statistical analysis}

Baseline characteristics were reported using descriptive statistics.

We used Spearman's rank correlation to analyze the association between duration of the third stage of labor and blood loss parameters (MBL and $\Delta-\mathrm{Hb}$ ).

The results prompted two subgroup analyses. First, we compared characteristics between women with a third stage shorter vs longer than $60 \mathrm{~min}$. As explained above, our hospital policy required MROP and the presence of an anesthesiologist if the placenta was retained beyond $30 \mathrm{~min}$, assuming no increase in bleeding. We considered the preparation time for anesthesia and further logistics and hence chose a $60 \mathrm{~min}$ cut off for third stage duration. Second, having observed a significant difference in the incidence of uterine atony (shown by our data to be the main risk factor for increased postpartum blood loss in women with retained placenta), we compared women with uterine atony and those without.

In the subgroup analyses, we used Fisher's exact test for categorical variables and the Mann-Whitney $U$ test for continuous variables. To investigate the relationship between MBL and each subgroup (third stage $<60$ vs $\geq 60 \mathrm{~min}$, and patients with vs without uterine atony), we used Spearman's rank correlation analysis. A $p$ value of $<0.05$ was deemed significant throughout. All analyses were performed using STATA version 12.1 (STATA Corp., TX, USA).

\section{Results}

The characteristics, risk factors and outcome parameters in the 296 women (Table 1) showed PPH in $96.6 \%$ of patients, mean MBL $1300 \mathrm{ml}$ (interquartile range [IQR] 900-1900 ml), and mean $\Delta-\mathrm{Hb} 39 \mathrm{~g} / \mathrm{l}$ (IQR 26-54 g/l); $4.5 \%$ of women needed blood transfusion. Correlation analysis, presented as scatterplots, showed no increase in MBL $(r=-0.06, p=0.311$; Fig. 1a) or decrease in hemoglobin $(r=-0.04, p=0.497$; Fig. 1b) with third stage duration.

Likewise, the first subgroup analysis (third stage $<60 \mathrm{~min}$ vs $\geq 60$ min, Table 2 ) revealed no significant differences in MBL, $\Delta-\mathrm{Hb}$ or frequency of PPH. In the shorter third stage subgroup, differences were significant in the need for blood transfusion $(9.8 \%$ vs $1.9 \%, p=0.006)$, presence of uterine atony $(39.8 \%$ vs $21.2 \%, p=0.001)$, frequency of operative vaginal delivery $(24.7 \%$ vs $11.3 \%, p=0.003)$, fetal head circumference ( $35 \mathrm{~cm}$ vs $34.5 \mathrm{~cm}, p=0.049$ ), frequency of multiple fetus pregnancy (6.5\% vs $1.5 \%, p=0.03)$, and postpartum regional anesthesia $(18.3 \%$ vs $58.6 \%, p<0.001)$.

The second subgroup analysis (Table 3 ) revealed that women with uterine atony were significantly more likely to experience a greater decrease in hemoglobin $(55 \mathrm{~g} / \mathrm{l} \mathrm{vs}$
Table 1 Characteristics and outcome parameters of all women with retained placenta

\begin{tabular}{|c|c|}
\hline Variables & $\begin{array}{l}\text { All } \\
n=296\end{array}$ \\
\hline \multicolumn{2}{|l|}{ Outcome parameters } \\
\hline$\Delta$-Hemoglobin $(\mathrm{g} / \mathrm{l})^{\mathrm{a}}$ & $39(26-54 \%)$ \\
\hline MBL (ml) & $1300(900-1900)$ \\
\hline $\mathrm{PPH}(\geq 500 \mathrm{ml})$ & $286(96.6 \%)$ \\
\hline Blood transfusion & $13(4.5 \%)$ \\
\hline \multicolumn{2}{|l|}{ Risk factors for increased blood loss } \\
\hline Uterine atony & $81(27.4 \%)$ \\
\hline Uterine myomas & $10(3.4 \%)$ \\
\hline $\mathrm{BL}$ due to maternal obstetric injuries ${ }^{\mathrm{b}}$ & $16(5.4 \%)$ \\
\hline Second stage labor (min) & $66(21-124.5)$ \\
\hline Second stage labor $>2 \mathrm{~h}$ & $77(26.0 \%)$ \\
\hline Third stage of labor (min) & $66(55-77)$ \\
\hline Operative vaginal delivery & $46(15.5 \%)$ \\
\hline Previous cesarean section & $16(5.4 \%)$ \\
\hline Morbidly adherent placenta & $42(14.2 \%)$ \\
\hline \multicolumn{2}{|l|}{ Feto-maternal characteristics } \\
\hline Fetal weight (g) & $3230(2805-3595)$ \\
\hline Fetal head circumference $(\mathrm{cm})$ & $34.5(33-35.5)$ \\
\hline GA (d) & $276.5(262-284)$ \\
\hline $\begin{array}{l}\text { Maternal body mass index first trimester }(\mathrm{kg} / \\
\left.\mathrm{m}^{2}\right)\end{array}$ & $21.5(19.85-24.6)$ \\
\hline Maternal age (y) & $33.8(30.5-36.6)$ \\
\hline Multiple fetus pregnancy & $9(3.0 \%)$ \\
\hline Multiparity & $129(43.6 \%)$ \\
\hline Primiparity & $167(56.4 \%)$ \\
\hline Fetal weight $\geq 4000 \mathrm{~g}$ & $16(5.41 \%)$ \\
\hline Induction of labor & $85(28.7 \%)$ \\
\hline Hypertensive disorders $^{\mathrm{c}}$ & $12(4.1 \%)$ \\
\hline \multicolumn{2}{|l|}{ Anesthetic characteristics } \\
\hline General anesthesia & $52(17.6 \%)$ \\
\hline Regional anesthesia pp & $136(46.0 \%)$ \\
\hline Admission to ICU pp & $6(2.0 \%)$ \\
\hline
\end{tabular}

Data are median (interquartile range) or $n(\%)$

$M B L$ measured blood loss; $P P H$ postpartum hemorrhage; $G A$ gestational age; $p p$ postpartum; $E D A$ epidural anesthesia; $I C U$ intensive care unit

${ }^{\mathrm{a}} \Delta$-Hemoglobin (g/l): difference in hemoglobin levels antepartum minus postpartum

${ }^{\mathrm{b}}$ Maternal obstetric injuries: cervical, vaginal or perineal tears

${ }^{\mathrm{c}}$ Hypertensive disorders include: prior existing hypertension, gestational-induced hypertension, preeclampsia and HELLP

$35 \mathrm{~g} / \mathrm{l}, p<0.001)$, increased MBL (2000 $\mathrm{ml}$ vs $1100 \mathrm{ml}$, $p<0.001)$, frequency of PPH ( $100 \%$ vs $95.4 \%, p=0.048)$, and need for blood transfusion $(13.6 \%$ vs $0.9 \%, p<0.001)$. This group was also more likely to have a shorter third stage (61.5 $\mathrm{min}$ vs $67 \mathrm{~min}, p=0.01)$, require general 


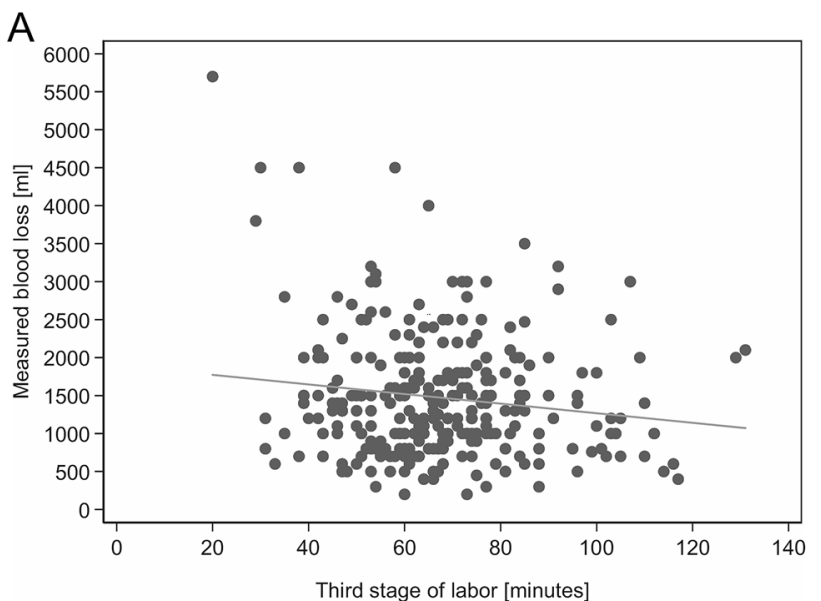

B

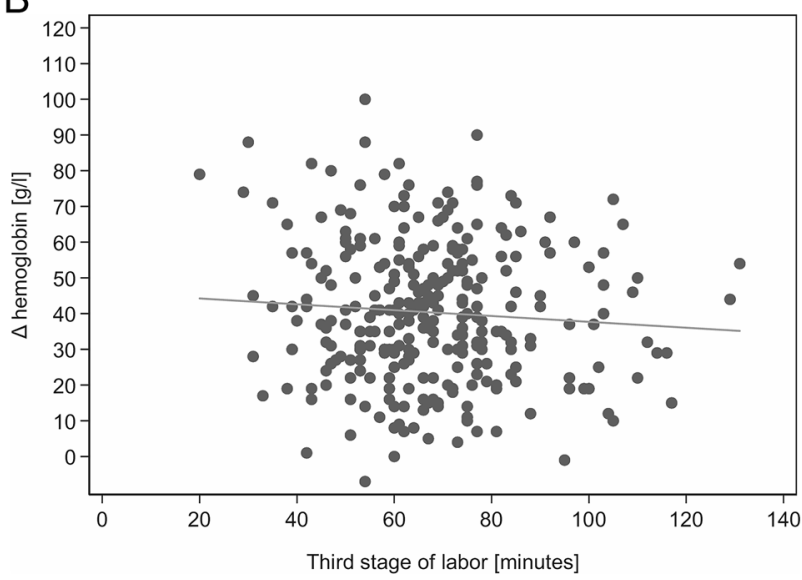

Fig. 1 a Correlation of duration of the third stage of labor with MBL (ml), all patients $(n=296), r=-0.06, p=0.311$. b Correlation of duration of the third stage of labor with $\Delta$-hemoglobin $(\mathrm{g} / \mathrm{l})$, all patients $(n=296), r=-0.04, p=0.497$

anesthesia (39.5\% vs $9.3 \%, p<0.001)$, and be admitted to intensive care postpartum ( $6.2 \%$ vs $0.5 \%, p=0.002)$.

As in the overall population, Spearman analysis found no significant correlation between MBL and third stage duration in all four subgroups (Fig. 2a-d).

\section{Discussion}

The association between postpartum blood loss and retained placenta, or duration of the third stage of labor, is a major obstetric concern. Consensus on an optimal MROP cut-off remains elusive [2-4, 6-9, 11, 12, 20]. Yet to our knowledge, the dynamics of blood loss over time had not previously been studied in a cohort confined to women with retained placenta. Our study with this population yielded no evidence for increasing blood loss with third stage duration. No definite MROP cut-off can thus be set.
Our finding conflicts with several earlier studies. Apparently, increased blood loss over time prompted proposals to end the third stage at $30 \mathrm{~min}[6,10]$. A 2008 review extended the cut-off to 30-60 min [20], while more recent studies even shortened it to 10-20 $\min [9,11,13,15,16]$.

However, these recommendations were derived from cohorts mainly comprising normal-duration third stages. Blanket cut-offs disregard retained placenta etiology [6, 9-11, 13-16], and clinical status. Given a mean $5.5 \mathrm{~min}$ for normal placenta delivery with active management [11], a preponderance of such cases could skew the analysis into suggesting that blood loss increases over time. In our population, no blood loss increase exists if the analysis is confined to women with retained placenta: blood loss in the third stage even decreases slightly and no difference over time is observed (Fig. 1). Our results are endorsed by another cohort study, which found that retained placenta as diagnosis itself was a strong predictor of quantity of blood loss, but that the bare duration of the third stage of labor, as in our study, was a weak predictor of quantity of blood loss [21]. Our findings suggest a pattern of blood loss dependent more on retained placenta etiology than on time. The frequency of uterine atony was $27.4 \%$, consistent with the increasing frequency of atonic PPH [22]. Our data support an association between shorter third stage of labor and uterine atony, characterized by immediate severe $\mathrm{PPH}$, hence significantly increased blood loss, decreased hemoglobin, and need for blood transfusion (Tables 2 and 3). Severity is underlined by significantly more admission to intensive care and need for general anesthesia. Thus, blood loss dynamics in uterine atony may partly explain the divergence between our results and those of previous researchers. Certainly, we cannot conclude that uterine atony would lead to a shorter third stage of labor or that shorter third stage of labor might be associated with uterine atony. Actually, we presume that uterine atony led to increased blood loss and consecutively to an earlier indication for MROP-irrespective of the time since delivery. A finding that underlines the importance of a close monitoring of women after the delivery of their child.

Only one randomized controlled trial has compared differing MROP cut-offs (10 vs $15 \mathrm{~min}$ ): it reported decreased hemodynamic compromise using $10 \mathrm{~min}$ [15]. Nevertheless, MROP is invasive, with its own risks, including increased blood loss and need for transfusion [10, 16, 23]. An early bonding and a positive birth experience may appear secondary considerations compared to the severity of PPH, but they must be factored into decision making given the multiple MROP interventions needed to prevent one case of hemodynamic compromise [24-26].

Hence, our reluctance to advocate blanket early MROP for retained placenta regardless of underlying etiology or clinical status before $30 \mathrm{~min}$ postpartum. Instead, we propose continuous third-stage monitoring for early signs of 
Table 2 Subgroup analysis on the duration of the third stage of labor $(<60 \mathrm{~min} ;>60 \mathrm{~min})$

\begin{tabular}{|c|c|c|c|}
\hline Variables & $\begin{array}{l}\text { Third stage of } \\
\text { labor }<60 \mathrm{~min} \\
(n=93)\end{array}$ & $\begin{array}{l}\text { Third stage of } \\
\text { labor } \geq 60 \mathrm{~min} \\
(n=203)\end{array}$ & $p$ value \\
\hline \multicolumn{4}{|l|}{ Outcome parameters } \\
\hline$\Delta$-Hemoglobin $^{\text {a }}(\mathrm{g} / \mathrm{l})$ & $38(28-56)$ & $39(25-54)$ & 0.676 \\
\hline MBL (ml) & $1400(900-2000)$ & $1300(900-1800)$ & 0.301 \\
\hline $\mathrm{PPH}(\geq 500 \mathrm{ml})$ & $92(98.9 \%)$ & $194(95.6 \%)$ & 0.124 \\
\hline Blood transfusion & $9(9.8 \%)$ & $4(1.9 \%)$ & 0.006 \\
\hline \multicolumn{4}{|l|}{ Risk factors for increased blood loss } \\
\hline Uterine atony & $37(39.8 \%)$ & $44(21.2 \%)$ & 0.001 \\
\hline Uterine myomas & $5(5.4 \%)$ & $5(2.5 \%)$ & 0.172 \\
\hline BL due to maternal obstetric injuries ${ }^{b}$ & $3(3.2 \%)$ & $13(6.4 \%)$ & 0.199 \\
\hline Second stage labor (min) & $87(27-155)$ & $47(20-119)$ & 0.058 \\
\hline Second stage labor $>2 \mathrm{~h}$ & $30(32.3 \%)$ & $47(23.2 \%)$ & 0.097 \\
\hline Third stage of labor (min) & $51(45-55)$ & $73(66-82)$ & $<0.001$ \\
\hline Operative vaginal delivery & $23(24.7 \%)$ & $23(11.3 \%)$ & 0.003 \\
\hline Previous cesarean section & $7(7.5 \%)$ & $9(4.4 \%)$ & 0.275 \\
\hline Morbidly adherent placenta & $15(16.1 \%)$ & $27(13.3 \%)$ & 0.517 \\
\hline \multicolumn{4}{|l|}{ Feto-maternal characteristics } \\
\hline Fetal weight $(\mathrm{g})$ & $3300(2900-3680)$ & $3190(2770-3560)$ & 0.091 \\
\hline Fetal head circumference $(\mathrm{cm})$ & $35(33.5-36)$ & $34.5(33-35.5)$ & 0.049 \\
\hline GA $(d)$ & $276(267-285)$ & $277(261-284)$ & 0.770 \\
\hline Maternal body mass index first trimester $\left(\mathrm{kg} / \mathrm{m}^{2}\right)$ & $21.4(20.3-24.1)$ & $21.5(19.8-24.9)$ & 0.859 \\
\hline Maternal age (y) & $33.54(29.9-36.44)$ & $34.08(30.52-36.66)$ & 0.561 \\
\hline Multiple fetus pregnancy & $6(6.5 \%)$ & $3(1.5 \%)$ & 0.030 \\
\hline Multiparity & $41(44.1 \%)$ & $88(43.4 \%)$ & 0.502 \\
\hline Primiparity & $52(55.9 \%)$ & $115(56.7 \%)$ & 0.498 \\
\hline Fetal weight $\geq 4000 \mathrm{~g}$ & $8(8.6 \%)$ & $8(3.9 \%)$ & 0.088 \\
\hline Induction of labor & $26(28.0 \%)$ & $59(29.2 \%)$ & 0.480 \\
\hline Hypertensive disorders $^{c}$ & $3(3.2 \%)$ & $9(4.4 \%)$ & 0.447 \\
\hline \multicolumn{4}{|l|}{ Anesthetic characteristics } \\
\hline General anesthesia & $21(22.6 \%)$ & $31(15.3 \%)$ & 0.125 \\
\hline Regional anesthesia pp & $17(18.3 \%)$ & $119(58.6 \%)$ & $<0.001$ \\
\hline Admission to ICU pp & $4(4.3 \%)$ & $2(1.0 \%)$ & 0.060 \\
\hline
\end{tabular}

Data are median (interquartile range) or $n(\%)$

$M B L$ measured blood loss; $P P H$ postpartum hemorrhage; $G A$ gestational age; $p p$ postpartum; $E D A$ epidural anesthesia; $I C U$ intensive care unit

${ }^{\mathrm{a}} \Delta$-Hemoglobin $(\mathrm{g} / \mathrm{l})$ : difference in hemoglobin levels antepartum minus postpartum

${ }^{\mathrm{b}}$ Maternal obstetric injuries: cervical, vaginal or perineal tears

${ }^{c}$ Hypertensive disorders include: prior existing hypertension, gestational-induced hypertension, preeclampsia and HELLP uterine atony or increased blood loss. Visual observation and vital parameter surveillance should be complemented by regular fundal palpation to assess tone and by ultrasonography to detect morbidly adherent placenta [27], detached but trapped placenta, and massive blood pooling in the atonic uterus without visible bleeding. Obstetric and anesthetist teams must be ready for MROP at any time should bleeding increase, irrespective of preset cut-offs. No safe time window exists, however early it is set.
We based our study on data manually collected by two experienced investigators (DF and JZ), double-checked by a third investigator $(\mathrm{CH})$. We used anesthetic protocols and obstetrician input to verify third-stage duration data. As for blood loss measurement-justifiably reported as error-prone [28-30] - the real-time technique used in every woman was developed in-house specifically to manage $\mathrm{PPH}$; feasibility and accuracy in the clinical setting were recently validated in 921 women [31]. 
Table 3 Patients with retained placenta with or without uterine atony

\begin{tabular}{|c|c|c|c|}
\hline Variables & Uterine atony $(n=81)$ & No uterine atony $(n=215)$ & $p$ value \\
\hline \multicolumn{4}{|l|}{ Outcome parameters } \\
\hline$\Delta$-Hemoglobin $(\mathrm{g} / \mathrm{l})^{\mathrm{a}}$ & $55(39-67.5)$ & $35(22-47)$ & $<0.001$ \\
\hline MBL (ml) & $2000(1500-2600)$ & $1100(800-1600)$ & $<0.001$ \\
\hline $\mathrm{PPH}(\geq 500 \mathrm{ml})$ & $81(100.0 \%)$ & $205(95.4 \%)$ & 0.048 \\
\hline Blood transfusion & $11(13.6 \%)$ & $2(0.9 \%)$ & $<0.001$ \\
\hline \multicolumn{4}{|l|}{ Risk factors for increased blood loss } \\
\hline Uterine myomas & $2(2.5 \%)$ & $8(3.7 \%)$ & 0.595 \\
\hline $\mathrm{BL}$ due to maternal obstetric ${ }^{\mathrm{b}}$ injuries & $4(4.9 \%)$ & $12(5.6 \%)$ & 0.821 \\
\hline Second stage labor (min) & $69(21-127)$ & $60(21-122)$ & 0.814 \\
\hline Second stage labor $>2 \mathrm{~h}$ & $23(28.4 \%)$ & $54(25.1 \%)$ & 0.566 \\
\hline Third stage of labor (min) & $61.5(50-73.5)$ & $67(59-77)$ & 0.010 \\
\hline Operative vaginal delivery & $13(16.1 \%)$ & $33(15.4 \%)$ & 0.882 \\
\hline Previous caesarean section & $7(8.6 \%)$ & $9(4.2 \%)$ & 0.131 \\
\hline Morbidly adherent placenta & $14(17.3 \%)$ & $28(13.0 \%)$ & 0.349 \\
\hline \multicolumn{4}{|l|}{ Feto-maternal characteristics } \\
\hline Fetal weight (g) & $3240(2900-3690)$ & $3220(2760-3570)$ & 0.264 \\
\hline Fetal head circumference $(\mathrm{cm})$ & $34.5(33.5-36)$ & $34.5(33-35.5)$ & 0.307 \\
\hline GA (d) & $278(269-284)$ & $276(262-284)$ & 0.381 \\
\hline Maternal body mass index first trimester $\left(\mathrm{kg} / \mathrm{m}^{2}\right)$ & $21.3(20.1-24.7)$ & $21.5(19.8-24.5)$ & 0.957 \\
\hline Maternal age (y) & $34.5(31.7-37.2)$ & $33.6(30.2-36.5)$ & 0.248 \\
\hline Multiple fetus pregnancy & $3(3.7 \%)$ & $6(2.8 \%)$ & 0.683 \\
\hline Multiparity & $38(46.9 \%)$ & $91(42.3 \%)$ & 0.478 \\
\hline Primiparity & $43(53.1 \%)$ & $124(57.7 \%)$ & 0.522 \\
\hline Fetal weight $\geq 4000 \mathrm{~g}$ & $4(4.9 \%)$ & $12(5.6 \%)$ & 0.827 \\
\hline Induction of labor & $28(34.6 \%)$ & $57(26.5 \%)$ & 0.172 \\
\hline Hypertensive disorders ${ }^{c}$ & $6(7.4 \%)$ & $6(2.8 \%)$ & 0.073 \\
\hline \multicolumn{4}{|l|}{ Anesthetic characteristics } \\
\hline General anesthesia & $32(39.5 \%)$ & $20(9.3 \%)$ & $<0.001$ \\
\hline Regional anesthesia pp & $26(32.1 \%)$ & $110(51.2 \%)$ & 0.003 \\
\hline Admission to ICU postpartum & $5(6.2 \%)$ & $1(0.5 \%)$ & 0.002 \\
\hline
\end{tabular}

Data are median (interquartile range) or $n(\%)$

$M B L$ measured blood loss; $P P H$ postpartum hemorrhage; $G A$ gestational age; $p p$ postpartum; $E D A$ epidural anesthesia; $I C U$ intensive care unit

${ }^{\mathrm{a}} \Delta-\mathrm{Hb}(\mathrm{g} / \mathrm{l})$ : difference in hemoglobin levels antepartum minus postpartum

${ }^{b}$ Maternal obstetric injuries: cervical, vaginal or perineal tears

${ }^{c}$ Hypertensive disorders include: prior existing hypertension, gestational induced hypertension, preeclampsia and HELLP

Possible methodological limitations include retrospective data evaluation, making precise etiology impossible to determine. For example, we do not have data regarding labor augmentation with oxytocin during the second stage of labor and its effect on PPH. Furthermore, the single-center design may cause selection bias, although ensuring that all women were treated by the same protocol. We cannot know whether atony caused a fully or partially retained placenta with immediately increased blood loss or whether atony with blood loss was observed only after MROP. However, there was no correlation between MBL and third stage duration in either the overall population or any subgroup. A further limitation is the possibly underestimated frequency of morbidly adherent placenta: placental histology was only requested if the obstetrician performing MROP clinically suspected the diagnosis. Furthermore, this diagnosis is most reliable only in case of hysterectomy with histopathological follow-up $(n=3)$.

\section{Conclusion}

In summary, we found no evidence for increased blood loss over time in the third stage. We therefore cannot identify a safe time window. Our analysis indicates that women with atonic retained placenta risk immediate severe hemorrhage 

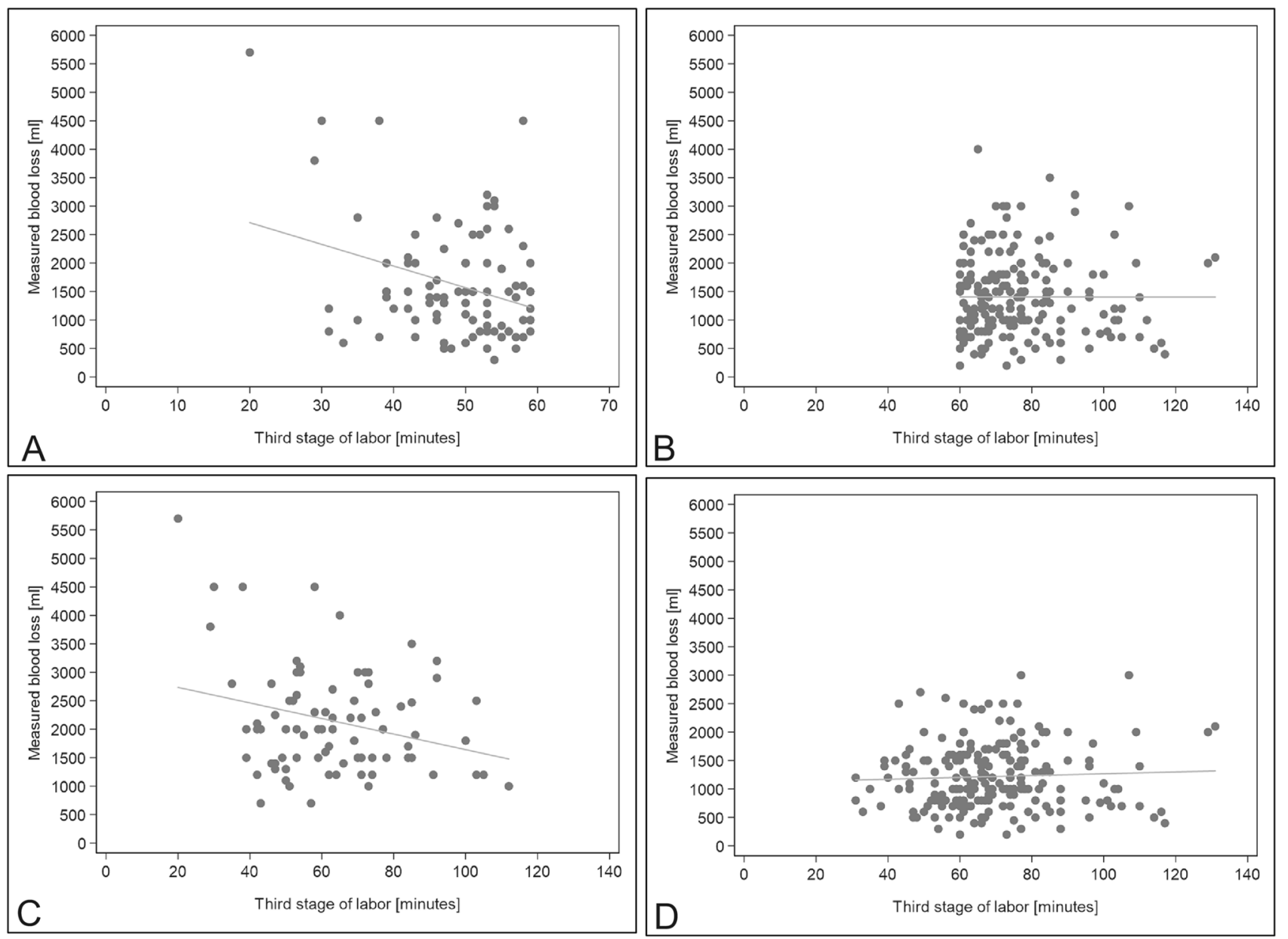

Fig. 2 a-d Correlation analysis between the duration of the third stage of labor and measured blood loss (MBL) (ml) of: a patients with a third stage of labor $<60 \mathrm{~min}, \mathbf{b}$ patients with a third stage of labor $\geq 60 \mathrm{~min}$, $\mathbf{c}$ patients with uterine atony, $\mathbf{d}$ patients without uterine atony). a Correlation of duration of the third stage of labor with MBL $(\mathrm{ml})$, in patients with third stage duration $<60 \mathrm{~min}(n=93)$, $r=-0.14, p=0.178$. b Correlation of duration of the third stage of

and have a significant higher need for blood transfusion. Delay can only compound blood loss. Prompt diagnosis followed by emergency MROP is required regardless of set cut-offs. In retained placenta with no increased blood loss in the non-atonic patient, a blanket policy of early cut-off could constitute overtreatment, hence our reluctance to recommend MROP before 30 min postpartum. We rather promote a close monitoring of the woman and a well-organized setting to be able to react promptly.

Author contribution DF: data collection, protocol/project development, data analysis, manuscript writing. $\mathrm{CH}$ : data collection, data management, protocol/project development, data analysis, manuscript review. JZ: data collection, research, manuscript review. TB: data analysis, manuscript review. PS: collection and analysis of anesthesiologic data, manuscript review. RZ: manuscript review. labor with $\mathrm{MBL}(\mathrm{ml})$, in patients with third stage duration $\geq 60 \mathrm{~min}$ $(n=203), r=-0.14, p=0.178$. c Correlation of duration of the third stage of labor with MBL $(\mathrm{ml})$, in patients with uterine atony $(n=81)$, $r=-0.06, p=0.311$. d Correlation of duration of the third stage of labor with MBL $(\mathrm{ml})$, in patients without uterine atony $(n=215)$, $r=0.05, p=0.470$

Funding Open Access funding provided by Universität Zürich. No funding was received.

\section{Declarations}

Conflicts of interest The authors declare that they have no conflict of interest.

Open Access This article is licensed under a Creative Commons Attribution 4.0 International License, which permits use, sharing, adaptation, distribution and reproduction in any medium or format, as long as you give appropriate credit to the original author(s) and the source, provide a link to the Creative Commons licence, and indicate if changes were made. The images or other third party material in this article are included in the article's Creative Commons licence, unless indicated otherwise in a credit line to the material. If material is not included in the article's Creative Commons licence and your intended use is not permitted by statutory regulation or exceeds the permitted use, you will 
need to obtain permission directly from the copyright holder. To view a copy of this licence, visit http://creativecommons.org/licenses/by/4.0/.

\section{References}

1. Say L, Chou D, Gemmill A, Tuncalp O, Moller AB, Daniels J, Gulmezoglu AM, Temmerman M, Alkema L (2014) Global causes of maternal death: a WHO systematic analysis. Lancet Glob Health 2(6):e323-333. https://doi.org/10.1016/S2214$109 X(14) 70227-X$

2. Al-Zirqi I, Vangen S, Forsen L, Stray-Pedersen B (2008) Prevalence and risk factors of severe obstetric haemorrhage. BJOG 115(10):1265-1272. https://doi.org/10.1111/j.1471-0528.2008. 01859.x

3. Coviello EM, Grantz KL, Huang CC, Kelly TE, Landy HJ (2015) Risk factors for retained placenta. Am J Obstet Gynecol 213(6):864 e861-864 e811. https://doi.org/10.1016/j.ajog.2015. 07.039

4. Nyflot LT, Sandven I, Stray-Pedersen B, Pettersen S, Al-Zirqi I, Rosenberg M, Jacobsen AF, Vangen S (2017) Risk factors for severe postpartum hemorrhage: a case-control study. BMC Pregnancy Childbirth 17(1):17. https://doi.org/10.1186/ s12884-016-1217-0

5. Sheiner E, Sarid L, Levy A, Seidman DS, Hallak M (2005) Obstetric risk factors and outcome of pregnancies complicated with early postpartum hemorrhage: a population-based study. J Matern Fetal Neonatal Med 18(3):149-154. https://doi.org/10. 1080/14767050500170088

6. Combs CA, Laros RK Jr (1991) Prolonged third stage of labor: morbidity and risk factors. Obstet Gynecol 77(6):863-867

7. WH Organisation (2009) WHO guidelines for the management of postpartum haemorrhage and retained placenta. World Health Organisation, Geneva

8. Cheung WM, Hawkes A, Ibish S, Weeks AD (2011) The retained placenta: historical and geographical rate variations. J Obstet Gynaecol 31(1):37-42. https://doi.org/10.3109/01443615.2010. 531301

9. Magann EF, Evans S, Chauhan SP, Lanneau G, Fisk AD, Morrison JC (2005) The length of the third stage of labor and the risk of postpartum hemorrhage. Obstet Gynecol 105(2):290-293. https:// doi.org/10.1097/01.AOG.0000151993.83276.70

10. Dombrowski MP, Bottoms SF, Saleh AA, Hurd WW, Romero R (1995) Third stage of labor: analysis of duration and clinical practice. Am J Obstet Gynecol 172(4 Pt 1):1279-1284

11. Frolova AI, Stout MJ, Tuuli MG, Lopez JD, Macones GA, Cahill AG (2016) Duration of the third stage of labor and risk of postpartum hemorrhage. Obstet Gynecol 127(5):951-956. https://doi. org/10.1097/AOG.0000000000001399

12. Deneux-Tharaux C, Macfarlane A, Winter C, Zhang WH, Alexander S, Bouvier-Colle MH, Group E (2009) Policies for manual removal of placenta at vaginal delivery: variations in timing within Europe. BJOG 116(1):119-124. https://doi.org/10.1111/j. 1471-0528.2008.01996.x

13. Cummings K, Doherty DA, Magann EF, Wendel PJ, Morrison JC (2016) Timing of manual placenta removal to prevent postpartum hemorrhage: is it time to act? J Matern Fetal Neonatal Med 29(24):3930-3933. https://doi.org/10.3109/14767058.2016.11549 41

14. Magann EF, Doherty DA, Briery CM, Niederhauser A, Morrison JC (2006) Timing of placental delivery to prevent post-partum haemorrhage: lessons learned from an abandoned randomised clinical trial. Aust N Z J Obstet Gynaecol 46(6):549-551. https:// doi.org/10.1111/j.1479-828X.2006.00658.x

15. Magann EF, Niederhauser A, Doherty DA, Chauhan SP, Sandlin AT, Morrison JC (2012) Reducing hemodynamic compromise with placental removal at 10 versus 15 minutes: a randomized clinical trial. Am J Perinatol 29(8):609-614. https://doi.org/10. 1055/s-0032-1311985

16. Shinar S, Schwartz A, Maslovitz S, Many A (2016) How long is safe? Setting the cutoff for uncomplicated third stage length: a retrospective case-control study. Birth 43(1):36-41. https://doi. org/10.1111/birt.12200

17. Eshkoli T, Weintraub AY, Sergienko R, Sheiner E (2013) Placenta accreta: risk factors, perinatal outcomes, and consequences for subsequent births. Am J Obstet Gynecol 208(3):219 e211-217. https://doi.org/10.1016/j.ajog.2012.12.037

18. Schlembach D, Helmer H, Henrich W, von Heymann C, Kainer F, Korte W, Kuhnert M, Lier H, Maul H, Rath W, Steppat S, Surbek D, Wacker J (2018) Peripartum haemorrhage, diagnosis and therapy. Guideline of the DGGG, OEGGG and SGGG (S2k Level, AWMF Registry No. 015/063, March 2016). Geburtshilfe Frauenheilkd 78(4):382-399. https://doi.org/10.1055/a-0582-0122

19. Prevention and management of postpartum haemorrhage: greentop guideline no. 52 (2017). BJOG 124(5):e106-e149. https://doi. org/10.1111/1471-0528.14178

20. Weeks AD (2008) The retained placenta. Best Pract Res Clin Obstet Gynaecol 22(6):1103-1117. https://doi.org/10.1016/j. bpobgyn.2008.07.005

21. Edwards HM, Svare JA, Wikkelso AJ, Lauenborg J, LanghoffRoos J (2019) The increasing role of a retained placenta in postpartum blood loss: a cohort study. Arch Gynecol Obstet 299(3):733-740. https://doi.org/10.1007/s00404-019-05066-3

22. Lutomski JE, Byrne BM, Devane D, Greene RA (2012) Increasing trends in atonic postpartum haemorrhage in Ireland: an 11-year population-based cohort study. BJOG 119(3):306-314. https://doi. org/10.1111/j.1471-0528.2011.03198.x

23. Wilkinson C, Enkin MW (2000) Manual removal of placenta at caesarean section. Cochrane Database Syst Rev (2):CD000130. https://doi.org/10.1002/14651858.CD000130

24. Christensson K, Cabrera T, Christensson E, Uvnas-Moberg K, Winberg J (1995) Separation distress call in the human neonate in the absence of maternal body contact. Acta Paediatr 84(5):468-473

25. Moore ER, Anderson GC, Bergman N, Dowswell T (2012) Early skin-to-skin contact for mothers and their healthy newborn infants. Cochrane Database Syst Rev (5):CD003519. https://doi. org/10.1002/14651858.CD003519.pub3

26. Saxton A, Fahy K, Hastie C (2014) Effects of skin-to-skin contact and breastfeeding at birth on the incidence of PPH: a physiologically based theory. Women Birth 27(4):250-253. https://doi.org/ 10.1016/j.wombi.2014.06.004

27. Krapp M, Baschat AA, Hankeln M, Gembruch U (2000) Gray scale and color Doppler sonography in the third stage of labor for early detection of failed placental separation. Ultrasound Obstet Gynecol 15(2):138-142. https://doi.org/10.1046/j.1469-0705. 2000.00063.x

28. Bose P, Regan F, Paterson-Brown S (2006) Improving the accuracy of estimated blood loss at obstetric haemorrhage using clinical reconstructions. BJOG 113(8):919-924. https://doi.org/10. 1111/j.1471-0528.2006.01018.x

29. Conner SN, Tuuli MG, Colvin R, Shanks AL, Macones GA, Cahill AG (2015) Accuracy of estimated blood loss in predicting need for transfusion after delivery. Am J Perinatol 32(13):1225-1230. https://doi.org/10.1055/s-0035-1552940

30. Schorn MN (2010) Measurement of blood loss: review of the literature. J Midwifery Womens Health 55(1):20-27. https://doi. org/10.1016/j.jmwh.2009.02.014 
31. Kahr MK, Brun R, Zimmermann R, Franke D, Haslinger C (2018) Validation of a quantitative system for real-time measurement of postpartum blood loss. Arch Gynecol Obstet 298(6):1071-1077. https://doi.org/10.1007/s00404-018-4896-0
Publisher's Note Springer Nature remains neutral with regard to jurisdictional claims in published maps and institutional affiliations. 